Prepared for the U.S. Department of Energy

under Contract DE-AC05-76RL01830

\title{
Challenges in Modeling the Degradations of Ceramic Waste Forms
}

R Devanathan

F Gao

$X$ Sun

September 2011

Pacific Northwest

NATIONAL LABORATORY

Proudly Operated by Battelle Since 1965 


\title{
DISCLAIMER
}

This report was prepared as an account of work sponsored by an agency of the United States Government. Neither the United States Government nor any agency thereof, nor Battelle Memorial Institute, nor any of their employees, makes any warranty, express or implied, or assumes any legal liability or responsibility for the accuracy, completeness, or usefulness of any information, apparatus, product, or process disclosed, or represents that its use would not infringe privately owned rights. Reference herein to any specific commercial product, process, or service by trade name, trademark, manufacturer, or otherwise does not necessarily constitute or imply its endorsement, recommendation, or favoring by the United States Government or any agency thereof, or Battelle Memorial Institute. The views and opinions of authors expressed herein do not necessarily state or reflect those of the United States Government or any agency thereof.

\author{
PACIFIC NORTHWEST NATIONAL LABORATORY \\ operated by \\ BATTELLE \\ for the \\ UNITED STATES DEPARTMENT OF ENERGY \\ under Contract DE-AC05-76RL01830
}

Printed in the United States of America
Available to DOE and DOE contractors from the Office of Scientific and Technical Information,
P.O. Box 62, Oak Ridge, TN 37831-0062;
ph: (865) 576-8401
fax: $(865)$ 576-5728
email: reports@adonis.osti.gov

\begin{abstract}
Available to the public from the National Technical Information Service, U.S. Department of Commerce, 5285 Port Royal Rd., Springfield, VA 22161 ph: (800) 553-6847 fax: $(703) 605-6900$ email: orders@ntis.fedworld.gov online ordering: http://www.ntis.gov/ordering.htm
\end{abstract}

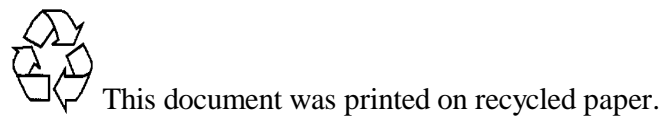




\title{
Waste IPSC Project Report
}

\section{Challenges in Modeling the Degradation of Ceramic Waste Forms}

\author{
August 2011 \\ Ram Devanathan ${ }^{1}$, Fei Gao ${ }^{1}$, Xin Sun $^{1}$ \\ ${ }^{1}$ Pacific Northwest National Laboratory, Richland, WA 99352
}

\begin{abstract}
We identify the state of the art, gaps in current understanding, and key research needs in the area of modeling the long-term degradation of ceramic waste forms for nuclear waste disposition. The directed purpose of this report is to define a roadmap for Waste IPSC needs to extend capabilities of waste degradation to ceramic waste forms, which overlaps with the needs of the subcontinuum scale of FMM (fundamental methods and method) interests. The key knowledge gaps are in the areas of i) methodology for developing reliable interatomic potentials to model the complex atomic-level interactions in waste forms; ii) characterization of water interactions at ceramic surfaces and interfaces; and iii) extension of atomic-level insights to the long time and distance scales relevant to the problem of actinide and fission product immobilization.
\end{abstract}




\section{Introduction}

The safe long-term immobilization of high-level nuclear waste, actinides and fission products in spent nuclear fuel, and plutonium from nuclear weapons, is a global Grand Challenge problem. With growing interest in the expansion of nuclear energy to reduce greenhouse gas emissions arising from energy use, the issue of nuclear waste disposal has gained renewed importance. Toxic radioisotopes with long half-lives $\left(\sim 24200\right.$ years for $\left.{ }^{239} \mathrm{Pu}\right)$ have to be isolated from the biosphere with confidence that they will not be released into the groundwater within a time scale of the order of tens of thousands of years or longer. Short-lived fission products, such as ${ }^{90} \mathrm{Sr}$ and ${ }^{137} \mathrm{Cs}$, produce heat through radioactive decay, which can accelerate chemical alteration of the waste form during the first 100 years of storage. In addition, highly mobile isotopes, such as ${ }^{129} \mathrm{I}$ and ${ }^{99} \mathrm{Tc}$, pose special challenges to the nuclear waste immobilization.

The international consensus on waste disposal [1] favors emplacement of waste in a stable geological formation with multiple engineered barriers to radionuclide release, including the waste form, waste container, drip shields, and compacted clay, augmenting natural barriers such as unsaturated rock. The solid waste form represents the first and most essential safeguard in any long-term waste disposal strategy. Borosilicate glass is currently the preferred waste form for high-level waste [2]. Glass has the advantages that it is easy to process; vitrification technology is well established; it can accommodate a variety of waste streams because of its chemical flexibility; and it is unlikely to undergo extensive structural changes during storage given its amorphous structure. However, glass has the disadvantages that the waste loading has to be small; devitrification is possible; glass tends to crack easily; and glass is not chemically durable in that it tends to degrade and release radionuclides over the long term [3]. As an alternative to borosilicate glass, radiation-tolerant ceramics tailored for specific waste streams and high waste loading have been the subjects of active research for nearly six decades [2-11].

Radionuclides can be distributed in a ceramic waste form in a number of different ways. They can be accommodated on a specific lattice site, such as the Gd site in $\mathrm{Gd}_{2} \mathrm{Zr}_{2} \mathrm{O}_{7}$, in a single phase ceramic. The stability of this arrangement depends on the ionic radius, type of bonding, and charge balance considerations that may result in creation of lattice defects for the case of aliovalent substitution [8]. Grains of radioactive phases can be also embedded in a ceramic matrix [8]. Polyphase ceramics [6], such as Synroc and Supercalcine, are equivalent to a synthetic rock made of multiple ceramic phases. For instance, Synroc-A consists of hollandite $\left(\mathrm{BaAl}_{2} \mathrm{Ti}_{6} \mathrm{O}_{16}\right)$, perovskite $\left(\mathrm{CaTiO}_{3}\right)$, zirconolite $\left(\mathrm{CaZrTi}_{2} \mathrm{O}_{7}\right)$, Ba-feldspar $\left(\mathrm{BaAl}_{2} \mathrm{Si}_{2} \mathrm{O}_{8}\right)$, kalsilite $\left(\mathrm{KAlSiO}_{4}\right)$, and leucite $\left(\mathrm{KAlSi}_{2} \mathrm{O}_{6}\right)$. Synroc-C consists of hollandite to immobilize $\mathrm{Cs}$, zirconolite to immobilize actinides, perovskite to incorporate $\mathrm{Sr}$, and rutile. It can accommodate up to $20 \%$ loading of high-level waste [11]. Synroc shows good radiation tolerance, and its resistance to leaching has been shown to be far superior to that of glass in laboratory experiments [6]. Other ceramic phases proposed for actinide immobilization include fluorite-structured 
ceramics, pyrochlores, muratite, garnet-structured ferrites, zircon, apatite, sphene, pollucite, monazite and xenotime [3,11].

The desirable characteristics proposed for waste forms [11] include high aqueous durability, high chemical flexibility to accommodate a variety of substitutional elements, high waste loading to minimize the size and cost of the repository, excellent radiation tolerance over millennial time scales, low volume swelling to avoid stress accumulation, and the availability of natural analogs. The last criterion is important to evaluate the long-term performance of a waste form and to validate computer models. Some durable minerals, such as zircon, occur naturally with $\sim 100 \mathrm{ppm}$ to a few $\%$ of actinides and are known to be the oldest minerals on earth ( $\sim 400$ Myr old) [12]. However, natural analogs are available only for some ceramics of interest and the repository conditions may be different from that experienced by the mineral. The waste loading is also likely to be different. Another major research challenge is the difficulty in extrapolating from accelerated laboratory experiments, conducted over hours to months at orders of magnitude higher radiation dose rates and extreme chemical environments relative to anticipated repository conditions, and achieve a reliable understanding of the changes in physical, chemical, and mechanical properties of the waste form in a repository over 10000 years or longer. Moreover, the repository conditions over the life of the waste form are not well characterized and may include extreme conditions that cannot be reproduced in a laboratory.

The limitations posed by laboratory experiments and the study of natural analogs can be overcome by performing computer simulations to provide complementary information, model extreme conditions and what-if scenarios, and perform sensitivity analysis. Experiments in turn can serve to refine the model and validate the model predictions. Ongoing rapid increases in computing power, memory, bandwidth, and storage have made such an integrated approach to waste management feasible. However, existing modeling scheme are limited in their ability to seamlessly describe phenomena across length scales from nanometer to meter and timescales from nanosecond to millennium, which has limited the application of computer models to the evaluation of waste form performance. The aim of this report is to survey the state of current waste form modeling capabilities, identify knowledge gaps, and recommend future research directions. The scope has been restricted to waste forms as opposed to the whole repository to focus the effort to the principal barrier and to avoid uncertainties arising from the fact that an ultimate repository location has not been selected in most countries.

This report reflects needs at the subcontinuum scale that overlap FMM interests, but its directed purpose is to define a roadmap for Waste IPSC needs to extend capabilities of waste degradation to ceramics.

\section{Modeling Schemes}


Modeling of nuclear waste forms is essential to obtain fundamental understanding of atomic level processes and their influence on long term waste form performance under a variety of conditions. Given the many orders of magnitude in length and time involved in this endeavor, it is not feasible to use a single model to span this range. Hierarchical multiscale modeling schemes that involve several models applicable to different scales of the problem are well-suited to the task of studying waste forms as shown in Fig. 1. The key challenges in this approach are in the process of information passing or coupling between models (represented by arrows in Fig. 1), verifying and validating the at-scale models and the coupling, estimating the error propagation across scales, and finally quantifying the uncertainty of the overall model predictions.

At the most fundamental level, density functional theory (DFT) [13-19] is widely used to study the properties of point defects and impurities, such as formation, migration, and binding energies, in materials. At the heart of this method, is the Kohn-Sham equation [13] that provides an approximate solution for the electronic structure of materials through the exchangecorrelation functional. Many different functionals are available to the DFT practitioner. It is important to understand the strengths and limitations of these functionals, and reasons for discrepancies between results reported in the literature $[18,20]$. The strong localization of $\mathrm{f}$ electrons in materials that contain actinides is a challenge for DFT, because widely used functionals cannot treat localized electrons correctly. The use of hybrid functionals improves accuracy but increases the computational intensity of DFT. The current state of the art for actinide-bearing materials is the use of an additional mean-field Hubbard parameter, $\mathrm{U}$, to the Hamiltonian [21-23]. Schreckenbach and Shamov [24] have recently discussed the various approximations used in computational chemistry of actinides. Due to the limitations of current functionals, DFT results will quantitatively differ from experimental results [25].

Despite the above mentioned limitations, DFT calculations can serve as the foundation, i.e. the most accurate and reliable level possible, of the multiscale modeling scheme for crystalline ceramics. DFT-based molecular dynamics simulation [26] is increasingly being used to investigate the dynamical behavior of complex chemical systems. It is highly relevant to the study of nuclear waste forms, especially the interactions of water with model ceramic surfaces. Unfortunately, the reliability of DFT comes with high computational cost, which limits the application of this method to systems containing fewer than 1000 atoms for time scales of 1 nanosecond or less. This limitation makes it difficult to model realistic surfaces and interfaces, which hold the key to ceramic dissolution processes. Gale and Wright [25] have pointed out that despite the ongoing increases in computational power many problems of interest continue to lie beyond the scope of DFT. Therefore, the main value of DFT in the study of ceramic waste forms lies in its ability to provide reliable data to fill gaps where experimental data is not available and to parameterize the next higher scale (coarser model) in the modeling hierarchy. High 
throughput DFT calculations [27] can be used to rapidly screen waste form candidates and optimize waste form composition.

At the next higher level, simulations of systems containing a million to a trillion atoms are possible with classical molecular dynamics (MD) and Monte Carlo (MC) simulations, although the current state of the art for ceramics is about 1 billion atoms. In simulations of such scale the electronic degrees of freedom are ignored and complex interactions between atoms are simplified in the form of parameterized classical potentials also known as force fields. The potential plays a crucial role in the reliability of the simulations, and its proper determination, especially in the case of complex ceramic systems with multiple cation and anion sublattices, is essential to the success of MD. While important advances have been made towards obtaining accurate classical potentials for simple metallic systems [28], their construction, especially for non-metals and complex configurations, still remains a challenging and time consuming process.

Much of the difficulty in generating reliable potentials for ceramics is caused by the lack of well-defined procedure to obtain the optimal interaction parameters. Traditionally a limited set of experimental data from only one or, at best, several reference configurations is used in the fitting process. The resulting potential is not transferable and its accuracy in real dynamical simulations is questionable. This is especially so if the potential is parameterized with available equilibrium property data, but is subsequently used to model conditions far from equilibrium. Due to the time consuming nature of the fitting process, the parameters of interaction, once determined, remain fixed for the duration of the simulation. This restricts the applicability of traditional MD simulations to important class of problems that involve significant dynamical changes in the chemical environment, such as water-mineral surface interactions, species transport in an aqueous medium, defect clustering and precipitation, and interaction of adsorbates with nanoparticles.

Recently, van Duin et al [29, 30] have developed reactive force fields that permit bond breaking to model complex chemical environments without the computational cost of DFT. The important aspects of this force field are that each atom has a Gaussian charge distribution that can transfer to other atoms in response to changes in the local environment, the parameters are obtained from DFT calculations, and there are no predetermined reactive sites [30]. Reactive force fields are available for barium titanate [30], aluminum oxide [31], and silica [32]. Similarly, charge-optimized many-body potentials have been developed to model $\mathrm{Si} / \mathrm{SiO}_{2}$ and $\mathrm{Hf} / \mathrm{HfO}_{2}$ interfaces $[33,34]$. However, there remains the need to extend this methodology to the heavy-element compounds that are being considered as candidate ceramic waste forms.

Several non-reactive potentials have been used to model mineral-water interactions. CLAYFF is a general force field developed by Cygan et al [35] to describe water, hydroxyl ions, and surface species. It can be used to model clay, hydroxide and oxyhydroxide phases and their interfaces with aqueous solutions [35]. Rustad [36] has reviewed molecular models of the 
oxide-water interface. Recently, a dissociative water model was developed and used to model the chemisorption of water molecules at a silica surface [37]. Hughes et al [38] have used quantum mechanical calculations to fit partial charge shell models and rigid ion models to study water interactions with zeolites. The shell model [39] represents the polarizability of ions by modeling a given ion as a massive core attached by a spring to a massless shell. The shell model provides a good representation of the equilibrium phase of ceramics [40-42]. However, shell models are more computationally intensive than the corresponding rigid ion models.

A key research need to address the limitations of current interatomic potentials is the development of a new framework that offers a concise, systematic, and efficient procedure for generating parameters of the interatomic interaction. A promising approach to achieve this goal is the Force Matching Method (FMM) of Ercolessi and Adams [43]. The FMM uses a large amount of data obtained from $a b$ initio calculations of various configurations and Car-Parinello MD simulations [26] to fit the interatomic potential. Atomic forces are determined from first principles for a large number of configurations including geometries such as clusters, defects, surfaces, and liquids. The functional form and parameters of the potential are optimized to match the first principles forces by performing a minimization using more than a hundred parameters. The method is not limited to presently-used analytical forms, which is an advantage for the simulation of complex materials for which potentials do not exist at present. FMM has been successfully applied to the development of potentials for metals [44] and Si [45].

The starting point for this potential development effort is a database of configurations obtained from experimental data, and DFT calculations of perfect crystals, defect configurations and the amorphous state. Fig. 2 shows a flow chart of this approach. The fitting of the potential begins with an initial guess for the form of the interaction. The input configurations will be used to determine forces and energies using DFT. In addition to these forces, experimentally determined lattice and elastic constants of various polytypes can be included in the fit. The data elements of the fit can be assigned various relative weights. Several strategies can be used to speed up the process at this point. The calculations for different configurations can be delegated to an independent group of processors giving rise to a very efficient parallel calculation. Based on $a b$ initio forces, the classical potential can then be refined using a least-squares fit. The interatomic potential generator can be used as a stand-alone module, and the refined potential can be used to perform nanosecond to microsecond scale classical MD simulations of radiation effects in ceramics and ceramic-water interactions.

In addition, the potential-generation algorithm can be dynamically coupled to a classical MD simulation as shown in Fig. 3. By performing two concurrent simulations - a classical MD simulation of a large ceramic system and a smaller DFT calculation for a small region of interest, such as a crack tip, one can generate potentials for complex environments on the fly [46]. The larger MD simulation will define the region of interest and provide its coordinates for the DFTbased simulation, which in turn will refine the parameters of the interaction for the region of 
interest. By loosely coupling the two simulations, there is the potential to implement the method efficiently on thousands of processors. Such a scheme would be invaluable to model charge transfer processes in ceramics, especially at interfaces and near defect clusters or second phases. Adaptive quantum mechanics/molecular mechanics (QM/MM) schemes [47] in which water molecules can enter or leave the quantum mechanical region of interest can be quite valuable in studies of mineral-water interactions. However, major issues remain in the implementation of embedding methods, such as the need to rigorously define the boundary between the QM and MM regions and match forces at the interface [48].

At the mesoscale level, the kinetic Monte Carlo (KMC) method [49] and the phase field (PF) model [50] are very useful to extend the spatial and time regimes of the MD simulations to deal with defect accumulation and gas bubble nucleation, phase stability and phase transformation over years. This is essential for upscaling atomic-level calculations to the macroscopic regime of experimental measurements. The KMC and PF simulations depend on the inputs such as defect migration energies, entropies, binding energies, and thermodynamics of different phases, as well as the initial micro-structural features of the material. In $\mathrm{KMC}$, we consider a set of random and independent events $W_{i}$, that occur with average rates $r_{i}$ as a Poisson process. The sequence of events and the time between events can be constructed from a probability distribution that is weighted based on the rates of the events. As reactions and transitions occur during the simulation, the list of possible events and their rates have to be recalculated to trace the evolution of the system. The scale of the process adapts to the new $r_{i}$ and the system can be followed over much longer time scales relative to classical MD. The major stumbling block with $\mathrm{KMC}$ is that a list of all possible events and their rates must be known to carry out the simulation. These inputs can be determined from experimental data bases, or from data generated by first-principles calculations or classical MD simulations, but it can become an onerous task for systems with chemically and geometrically complex interfaces.

In contrast to the stochastic KMC method, the phase field model is a deterministic thermodynamic model that is used to describe microstructural evolution in terms of continuum phase field. The PF can be a descriptor of microstructure or composition. The field equations are solved on a two- or three-dimensional grid with grid spacing larger than the atomic scale but smaller than the grain scale. As in the case of the KMC method, the PF model requires considerable thermodynamic and kinetic input parameters from experiment or finer length scale simulations, such as defect formation, migration, binding and interaction energies. Without such information, reliable quantitative modeling is not possible. The results of mesoscale models can be used to develop constitutive equation describing material behavior.

\section{Modeling of ceramic waste forms}

Modeling and simulation studies of waste forms have focused mainly on atomistic details of radiation damage. Sickafus et al [51] predicted the radiation tolerance of $\mathrm{A}_{2} \mathrm{~B}_{2} \mathrm{O}_{7}$ pyrochlores 
using molecular statics calculations with fixed charge empirical potentials. Radiation tolerance was attributed to the ability of the material to tolerate lattice defects produced. Subsequent molecular statics studies of $\mathrm{A}_{4} \mathrm{~B}_{3} \mathrm{O}_{12}$ compounds [52] by the same group showed that radiation tolerance can be inferred from the phase diagram and that compounds that accommodate lattice disorder tend to resist amorphization. MD simulations of $\mathrm{A}_{2} \mathrm{~B}_{2} \mathrm{O}_{7}$ pyrochlore by Chartier et al $[53,54]$ have shown that the accumulation of dumbbell interstitials on the $\mathrm{B}$ cation sublattice results in amorphization and that the annealing of the dumbbells is kinetically not feasible at low temperatures. Recently, Devanathan et al [55] have used molecular statics calculations and MD simulations to examine the effects of defect accumulation on the structural and mechanical stability of $\mathrm{Gd}_{2} \mathrm{Zr}_{2} \mathrm{O}_{7}$ and $\mathrm{Gd}_{2} \mathrm{Ti}_{2} \mathrm{O}_{7}$ pyrochlores. The results reveal that seemingly minor differences in radiation damage accumulation and annealing between the two pyrochlores eventually lead to divergent responses to radiation. The cation Frenkel pair accumulation was found to drive $\mathrm{Gd}_{2} \mathrm{Ti}_{2} \mathrm{O}_{7}$ amorphous with a decrease in density of about $13 \%$ and decrease in elastic modulus of $50 \%$ while amorphization did not occur in $\mathrm{Gd}_{2} \mathrm{Zr}_{2} \mathrm{O}_{7}$ due to more effective dynamic annealing as shown in Fig. 4. Such effective dynamic annealing has also been observed in MD simulations of energetic recoil damage in yttria-stabilized zirconia (YSZ) [56], which has the related fluorite structure. Since $\mathrm{Gd}_{2} \mathrm{Zr}_{2} \mathrm{O}_{7}$ and $\mathrm{YSZ}$ are fast ion conductors [57], rapid anion vacancy migration helps to anneal damage and to prevent radiation damage accumulation from making the disordered crystal thermodynamically unstable with respect to the amorphous material. The combination of a mechanism to accommodate radiation damage with minimal increase in energy and volume and fast anion transport to enable dynamic annealing appears to be the key to radiation tolerance in compounds based on the fluorite structure $[52,55,58]$. High values of the displacement threshold energy, i.e. the minimum energy to be imparted to a lattice atom to produce a stable defect, seem to be good indicators of radiation tolerance of ceramics $[59,60]$.

Trachenko et al [61-66] have examined the amorphization resistance of a number of ceramics using atomistic simulation. They observed that the extent of radiation-induced structural damage has an effect on activation energy barriers for damage recovery and that the dynamic recovery processes at the picosecond scale have a strong influence on resistance to amorphization. Devanathan et al [67-69] performed MD simulations of energetic recoil damage in zircon and observed direct-impact amorphization. Unlike the case of zirconia and $\mathrm{Gd}_{2} \mathrm{Zr}_{2} \mathrm{O}_{7}$ pyrochlore in which isolated defects are produced by radiation damage, energetic recoils in zircon produce an amorphous core surrounded by defects as shown in Fig. 5. At the nanoscale, radiation damage induces phase separation into zirconia-rich and silica-rich regions [68]. Yu et al [70] found a $11 \%$ volume expansion and $60 \%$ decrease in bulk modulus as a result of amorphization of crystalline zircon. Large volume swelling can induce cracking of wasteforms and enable the leaching of actinides during long-term storage. Trachenko et al [65-66] have connected the amorphization resistance to the nature of the chemical bond by stating that a complex material can be amorphized by irradiation if it can form a covalent network. The 
authors have indicated that other criteria proposed in the literature such as those based on coordination number, radius ratio and topology may ultimately be tied to the nature of the chemical bond.

In addition to DFT calculations and MD simulations, the $\mathrm{kMC}$ method has been used to study the stochastic production of defects in the crystal lattice, recombination of defects, and the identification of amorphous regions in $\mathrm{ZrSiO}_{4}$ [71]. Within this model, amorphous regions were identified as those having a critical density of $\mathrm{Zr}$ vacancies. The simulated interstitial content and amorphous fraction as functions of dose were found to be consistent with experimental data at $300 \mathrm{~K}$ for ${ }^{238} \mathrm{Pu}$-doped zircon. While this simple model provides reasonable agreement with experimental data, it does not yet fully describe all the atomic- level processes associated with cascade overlap and relaxation. Further improvements in the model will require additional experimental data and realistic atomic-scale information from DFT calculations of defect reaction kinetics and defect relaxation. More recently, a hybrid kinetic lattice Monte Carlo (KLMC) model has been integrated with MD simulation and applied to investigate the recovery and clustering of defects during annealing of a single $10 \mathrm{keV}$ cascade in cubic silicon carbide [72]. A method of directly transferring the defects created by MD simulations to the KLMC model was developed, while the KLMC model parameters were obtained from MD simulations and $a b$ initio calculations of defect migration, recombination, and annihilation. The transfer of defect configurations between MD and Monte Carlo is important for multiple cascade defect accumulation simulations since the atomic relaxation during defect accumulation has to be properly considered. This overcomes an important weakness of previous KMC simulations of defect accumulation.

In addition to studies of defect accumulation and recoil damage in waste forms, there is growing interest in studying the response of ceramics to swift heavy ion (SHI) damage. Simulations of the electronic stopping process, for instance using a thermal spike model, can provide insights into the competition between amorphization and recrystallization in irradiated ceramics. Pakarinen et al [73] have studied SHI damage in quartz and amorphous silica. Their results shed light on the density variations in the radiation damaged region. Areas of lower density may provide pathways for actinide and other species diffusion. Crocombette [74] has compared defect production by displacement cascades and thermal spikes and concluded that while the number of defects produced in simulations of cascades and spikes can be different, the overall characteristics of the damage are quite similar. Recently, Zhang et al [75] showed that thermal spike simulations can reproduce the microstructural features of ion tracks and the amorphization tendency observed in experimental irradiation of pyrochlore compounds. These findings suggest that thermal spike simulations can be used to quickly screen candidate waste forms based on their tendency to undergo direct-impact amorphization.

While most simulations of radiation damage to date have focused on single crystals, there is growing interest in simulating defects and diffusion in polycrystalline materials. The kMC method has been used to explore the grain boundary diffusion in ceramics [76], which controls 
many solid-state processes such as sintering, creep, and the growth of oxide films on metals or ceramics. The basic problem with simulations of grain boundaries in ceramics is that the activation energies for ion motion are so high (of the order of $1 \mathrm{eV}$ ) that it is not feasible to extract diffusion coefficients from MD simulations except at unrealistic temperatures. The problem with using static simulations, on the other hand, is that boundaries often have a large number of different possible hops, all of low symmetry, so that it is difficult to find the saddle points and obtain the individual hopping rates. While the calculated activation energies for grainboundary diffusion are in reasonable agreement with experiment, problems in comparing the simulations with experiments performed on polycrystals are still issues to be addressed with further advances in simulation methods.

In contrast to the extensive atomic-level simulations of radiation damage in waste forms, there have been limited modeling studies of water interactions with waste form surfaces. Bates et al [77] have stated that existing models of actinide mobility may underestimate the possibility of radionuclide release. Nangia and Garrison [78] have reviewed the state of theory in the study of dissolution at mineral-water interfaces. Most of the studies performed to date have used atscale models and there is a need to span the gap from $a b$ initio studies of small clusters to continuum models of dissolution. Most of the studies have focused on silicate minerals. Ab initio molecular orbital calculations by Xiao and Lasaga [79] using disilicic acid, (HO) ${ }_{3} \mathrm{Si}-\mathrm{O}-$ $\mathrm{Si}(\mathrm{OH}))_{3}$, to represent the quartz surface have shed light on the rate-determining step in the dissolution of $\mathrm{SiO}_{2}$ by hydrolysis. This is at odds with the subsequent findings of Criscenti et al [80] based on a similar study using larger clusters and explicit water molecules, which demonstrates the need for simulating realistic waste form surfaces. However, modeling large surface structures using DFT is computationally expensive. At the next level, MD simulations have been used to study the reactivity of quartz surfaces using models of varying complexity, such as shell models and dissociative water models [81, 82]. Given the limited ability of MD simulations to go beyond a few hundred nanoseconds, kinetic models have been developed to describe dissolution at feldspar surfaces [83]. Recently a time-independent reactive Monte Carlo-configurational bias Monte Carlo hybrid algorithm has been developed to study dissolution at silicate-water interfaces [84]. As a part of the NEAMS Waste IPSC, Argonne National Laboratory has been used $a b$ initio (DFT) and molecular dynamics methods to calculate salvation and $\mathrm{pH}$ values in glass waste forms and to study the dissolution kinetics of orthoclase feldspar surfaces. These investigations have direct relevance to the ceramics waste forms at surfaces.

Stochastic methods can be used to improve our understanding of the dissolution process by testing basic assumptions of the analytical models [85]. In glasses, the simulated results predict the experimentally observed silica condensation that results in a protective effect of the alteration layer and an initial silica dissolution rate decreasing as a function of time [85]. The simulated results also demonstrate that the silica solubility in solution is not that of the highest energy state (the glass), but depend on the exact parameter values, which is consistent with the fact that most silica bearing sites at the surface with the solution are in that lowest energy state. 
This result confirmed that dissolution kinetics leads to different steady state concentrations than thermodynamic equilibrium, which would suggest that, if two energy sites exist, the observed solubility in solution corresponds to the site with the highest energy state. Instead, the observed solubility lies between the solubility corresponding to both sites and its value depends on the relative amounts of both sites. The silica solubility also depends on the amount of silica particles in contact with the solution (the surface), implying that replacing part of the silica by another poorly soluble glass network former lowers the silica solubility. However, the representation of the surfaces and materials in terms of composition in the Monte Carlo simulations are generally very simple, and the Monte Carlo predictions are qualitative, but not quantitative. Quantitative predictions require more atomic-level or thermodynamic parameters (e.g. a better description of the interaction between particles, greater chemical complexity in the model, and more complex surfaces). This will allow realistic simulations of wasteform dissolution.

Finally, it is worth noting that the phase field model has emerged as a powerful computational approach at the mesoscale for predicting phase stability and microstructural evolution under irradiation [86]. Phase field models have been developed to predict gas bubble microstructure evolution in nuclear fuels [86], void migration and growth kinetics in materials under irradiation and temperature field [87] shown in Fig. 6, void evolution and swelling in materials under irradiation [88], and void nucleation and growth in irradiated metals [89]. In these models, only the diffusion of single vacancies and interstitials is considered. Mobile defect clusters, such as vacancy clusters or small interstitial loops, are viewed as an assembly of individual vacancies or interstitials in this approach. Thus, they contribute to the overall defect concentrations and to the effective mobilities of defects. However, larger and immobile defect clusters are viewed as sinks or nucleation sites for defect clusters, which may affect the net generation rate of point defects. A general assumption is that vacancies and interstitials generated by fission fragments and neutron damage cascades can be absorbed by structural defects, such as dislocations and grain boundaries, and thus, the net increase of vacancies and interstitials depends on the generation rates of fission fragments and neutrons. This also depends on the defect generation rates, and sink strengths, which are determined by the type and density of point defect sinks. On the other hand, the driving force of vacancy and interstitial diffusion includes the chemical potential gradients and the concentration gradients, correlated with the microstructure evolution driven by the minimization of the total free energy of the system. Moreover, the microstructure evolution path depends on thermal fluctuations, defect generation, recombination, and defect sink interactions in irradiated materials. The simulated results for irradiated materials demonstrate the ability of phase-field approach to model the nonequilibrium process of microstructure evolution.

\section{Research needs}


The development of science-based models to predict the long-term behavior of ceramics waste forms for nuclear waste disposition represents an important opportunity that requires a fundamental understanding of atomic-level processes (such as defect generation and migration, incorporation of fission products, and their interactions with microstructures) and long term performance under extreme conditions (such as phase stability, phase transformation, radiation tolerance, and leaching under different temperature and $\mathrm{pH}$ conditions). Although significant progress has been made to model the complex behavior of ceramic nuclear waste forms, ranging from atomic-level processes to meso-scale mechanisms of radionuclide incorporation, chemical corrosion, and alteration mechanisms, and the response to different types of radiation fields, the present understanding of their performance over long time periods is insufficient in detail, even for the case of atomic-level simulations as outlined above. The ability to develop integrated models rests not only on our fundamental understanding of the critical processes but also on the computational ability to link atomic-level understanding to macroscopic phenomena. The challenge in making predictions about the long-term performance of a waste forms is to identify the key mechanisms governing fundamental processes in ceramics waste forms. Key research needs for ceramic nuclear waste forms are recommended below, with the primary objective to develop fundamental knowledge and models at the atomic, microscopic, and macroscopic levels in order to enable performance assessments under a variety of conditions.

(i) Advances in the basic science of $f$ electron systems in materials may offer the opportunity to extend condensed matter physics and reaction chemistry to accurately predict the performance of ceramic nuclear waste forms. This is a key enabling science for the fundamental understanding of actinide-bearing materials and solutions. Two major physical effects that challenge the theoretical modeling of $f$ electron systems are relativistic effects and dynamic correlation. Computational actinide chemistry has its own challenges, arising from the combined effects of relativity and electron correlation, along with the size of typical systems, the large number of electrons, and the close energetic proximity of several electronic states. As described above, a key research need is to develop a robust theory of the electronic structure or exchange and correlation functionals in density functional theory for actinide-bearing materials that will provide an improved understanding of their physical and chemical properties and behavior. Advances are needed in the application of these new electronic structure methods for $f$-elementcontaining molecules and solids to calculate the defect properties, incorporation of fission products and their interaction with microstructures in multi-component systems. Also, these improved developments will advance the fundamental understanding of related chemical and physical properties at high temperature.

(ii) Many ceramic forms with different crystal structures, such pyrochlore, zirconia and apatite, have been proposed as hosts for fission products (e.g. Cs, Sr and I), but they will be subjected to high ionizing radiation fields for a long period (up to several hundred years), where charge transfer, electronic excitations and electronic energy loss processes can enhance defect 
migration, promote defect recovery and influence microstructural evolution in ceramics [90]. Recent studies have used ab initio MD methods (AIMD) to study low energy recoil events in ceramics [91] and semiconductors [92, 93]. Large-scale ab initio MD methods have also been used to study ion-solid interactions in $\mathrm{SiC}$ [93], and the results demonstrate that significant charge transfer can occur between atoms, and defects can enhance charge transfer to the surrounding atoms. Moreover, the charge transfer to and from recoiling atoms can alter the energy barriers and dynamics for stable defect formation. These simulations have been limited to systems containing fewer than 1000 atoms and to time scales less than 1 nanosecond. Alternatively, Sutton et al. [94] have developed a large-scale tight binding molecular dynamics (TBMD) method capable of dealing with electronic and atomic dynamics for up to 100,000 atoms. This method has been applied to the physics of electron migration in nanowires, currentinduced heating, and electronic excitations and their influence on interatomic forces in radiation damage in metals [94]. However, the current model considers only the s-band with two sorbitals. While this single s-band model has been used to model radiation damage in metals, further developments including higher band models are needed to extend this method to ceramics, which will be crucial for the correct description of directional bonding in materials.

(iii) The use of empirical or semiempirical interatomic potentials makes it possible to simulate large systems ( $\sim$ up to a few billion atoms) for long times (microsecond), and thus to tackle such problems as defect generation, plastic deformation, ion-solid interaction, or atomic diffusion. However, the reliability of interatomic potentials is a key issue for the success of predictive models for ceramic waste forms. Due to the extensive use of MD methods in materials science, a variety of techniques have been utilized over the years to develop reliable atomic potentials. For ceramic waste forms, long-range Coulombic interaction with partial charge models along with short range interactions of the Buckingham form are generally employed to simulate radiation damage and defect accumulation. As discussed above, significant charge transfer can occur during irradiation, and the defects created can enhance charge transfer to the surrounding atoms. Furthermore, a major weakness of fixed-charge potentials is that an interstitial dumbbell made entirely of cations or anions is unlikely to form due to the strong Coulomb repulsion between like ions, which is in contrast to the findings of ab initio calculations. One possible solution is the development of charge transfer potentials [95], incorporating variable charge concepts into an analytical embedded-ion method (EIM) potential, where the equilibrium charges are embedded in the potential so that the energy minimization step is eliminated. As a result, the method is both energy conserving and computationally efficient. Using the La-Br system as an example, it has been demonstrated that this model captures key properties of the $\mathrm{LaBr}_{3}$ compound including the crystal structure, lattice geometry, and the $\{1120\}$ cleavage. The model can already provide a viable interatomic potential for nonstoichiometric ionic systems.

A generalized framework for interatomic potential design has been recently established [96], as shown in Fig. 7, which allows a researcher to tailor an interatomic potential towards specific properties. This methodology produces an interatomic potential design map, which 
contains multiple interatomic potentials and is capable of exploring different nanoscale phenomena observed in experiments. This methodology is efficient and provides the means to assess uncertainties in nanostructure properties due to the interatomic potential fitting process. New advances in the development of interatomic potentials using a large data base of force fields and atomic configurations, and in variable charge models, are needed to overcome the challenges of adequately treating defect properties, change transfer and radiation effects. For each potential, the limits of transferability must be established, and the potential must be validated for far-fromequilibrium conditions, such as unusual coordination, high temperature, and high pressure.

(iv) Waste form evolution over long-time scale (up to millennia) can involve extremely slow kinetic processes operating over geological time scales, such as leaching, internal radiation damage leading to amorphization or crystallization. The stability and safety of waste forms will depend on our knowledge of the details of interfacial chemistry and transport for the specific waste form and repository. New advances in mesoscale and macroscale modeling of ceramic waste forms need to focus on the development of methods and models to describe the fundamentals of surface chemical interactions to allow efficient modeling of multiple phase interfaces. While significant advances have been made in $\mathrm{kMC}$ methods and phase field models, they have been applied mainly to predict microstructural evolution in relatively simple systems, such as pure metals and simple alloys. Simulating defect processes and microstructure evolution of ceramic waste forms using the $\mathrm{kMC}$ method and phase field model is challenging in part because of the inherent chemical and structural complexity.

In addition, current $\mathrm{kMC}$ and phase field models of materials are often qualitative, but not quantitative. The development of quantitative $\mathrm{kMC}$ and phase-field models for ceramics is even more challenging because the systems involve complex reactions consisting of numerous steps, resulting in the formation of reactive or metastable intermediate species. Moreover, quantitative $\mathrm{kMC}$ and phase-field models require accurate thermodynamic and kinetic properties of the corresponding ceramics, which may represent long-term grand challenges of atomic-level simulations. Lacking thermodynamic and kinetic properties, the kMC and phase-field simulations may use reasonable thermodynamic and kinetic properties which could be obtained from experiments and atomistic simulations. These mesoscale simulations can be used to build a thermodynamic database of the effects of thermodynamic and kinetic parameters on the microstructural evolution of ceramic waste forms. Such a database could play an important role in uncertainty evaluation of both mesoscale and macro-scale simulations. At present, kMC and phase field approaches look promising for bridging the atomistic and continuum scales, particularly because they can be used to reproduce both near- and far-from equilibrium dissolution and to deal with water-mineral surface interactions, species transport in an aqueous medium, defect clustering and precipitation, and interaction of adsorbates with nanoparticles. Finally, there is a need to develop rigorous upscaling techniques to create accurate constitutive equations for continuum models, which can be used to evaluate the long-term performance of ceramic waste forms under a variety of environmental conditions. Continuum models are needed 
to account for microstructural evolution and property changes with radiation damage, thermochemistry and thermodynamics.

(v) Important issues that should be addressed in the framework of a multiscale and multiphysics model of ceramic waste forms include cross-verification of data obtained from different simulation codes, validation of simulation results using experimental data and finer scale models, and quantitative assessment of uncertainties at each scale and for the handshake between scales. The development of a standard verification, validation and uncertainty quantification approach is required for the multiscale scheme, and a similar approach needs to be developed for determining the reliability of data obtained from experiments. Data used and generated by subcontinuum and mesoscale models with different codes, methods, and algorithms need to be verified and validated, and properly qualified. In addition to developing methods for upscaling from finer to coarser scales, quantitative estimation of the propagation of uncertainties through the hierarchy of scales will be essential.

\section{Summary}

We have reviewed the state of the art and important research needs in modeling the degradation of ceramic waste forms. Despite decades of research, modeling studies have focused on simple crystal structures and simple chemistries, single crystals, and studies of radiation damage at the nanoscale. There is a need to expand these studies to complex chemistries and structures, including polycrystalline and polyphase materials. Given the reality that density functional theory will continue to be limited to short time and distance scales, there is a need to systematically coarse grain simulations of ceramic waste forms with rigorous verification, validation and uncertainty quantification. Reactive interatomic potentials have to be developed to model the complex interactions at ceramic surfaces and interfaces. Simulation of realistic surfaces, efficient coupling from atomistic simulations to stochastic models, and development of constitutive equations that can be used in continuum models will be crucial to advance this field.

\section{ACKNOWLEDGMENTS}

This report was supported by the US Department of Energy's Nuclear Energy Advance Modeling and Simulation (NEAMS) Program, within the Waste IPSC, in Pacific Northwest National Laboratory (PNNL), which is operated by Battelle Memorial Institute for the US Department of Energy under Contract No. DE-AC05-76RL01830. 


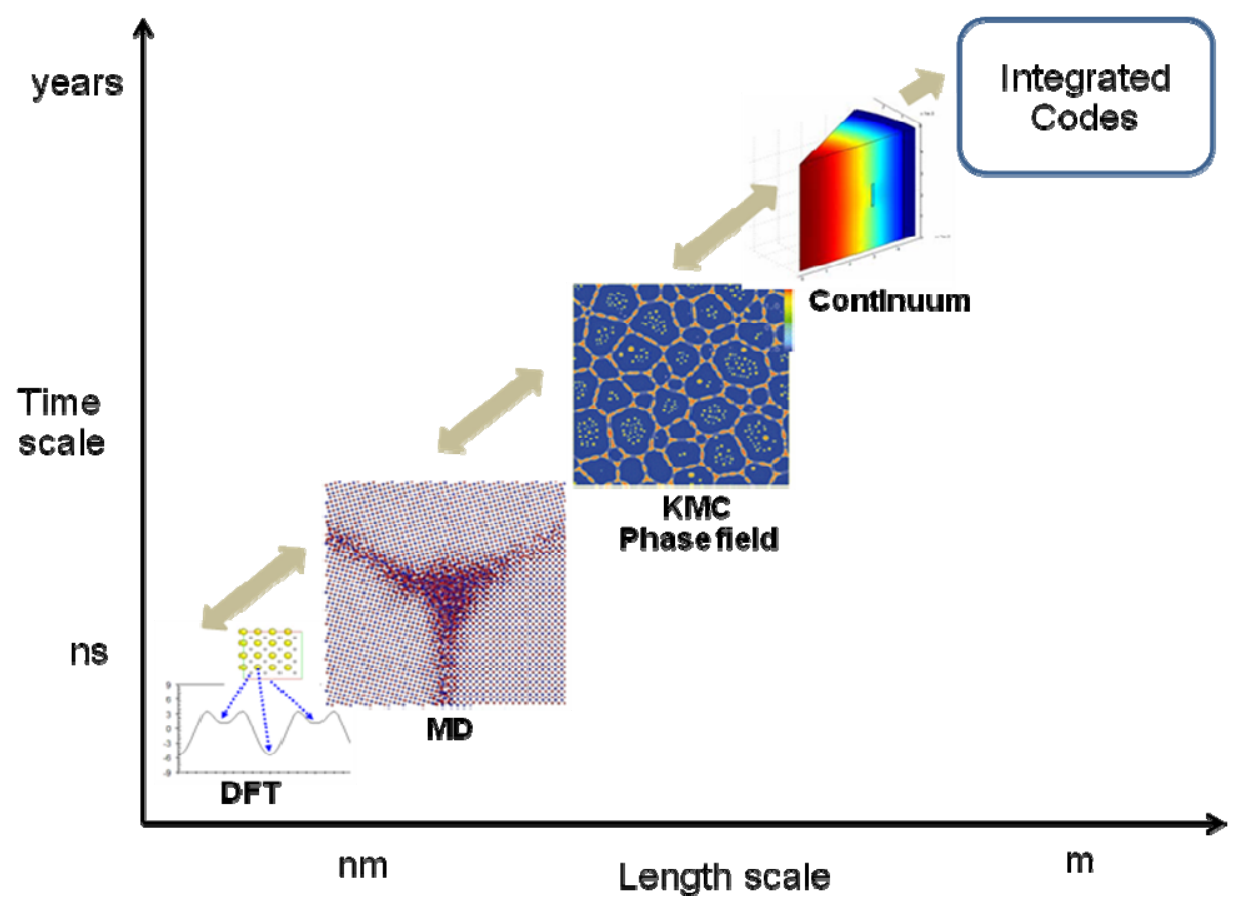

Figure 1. At-scale models in a multiscale modeling scheme for waste forms. 


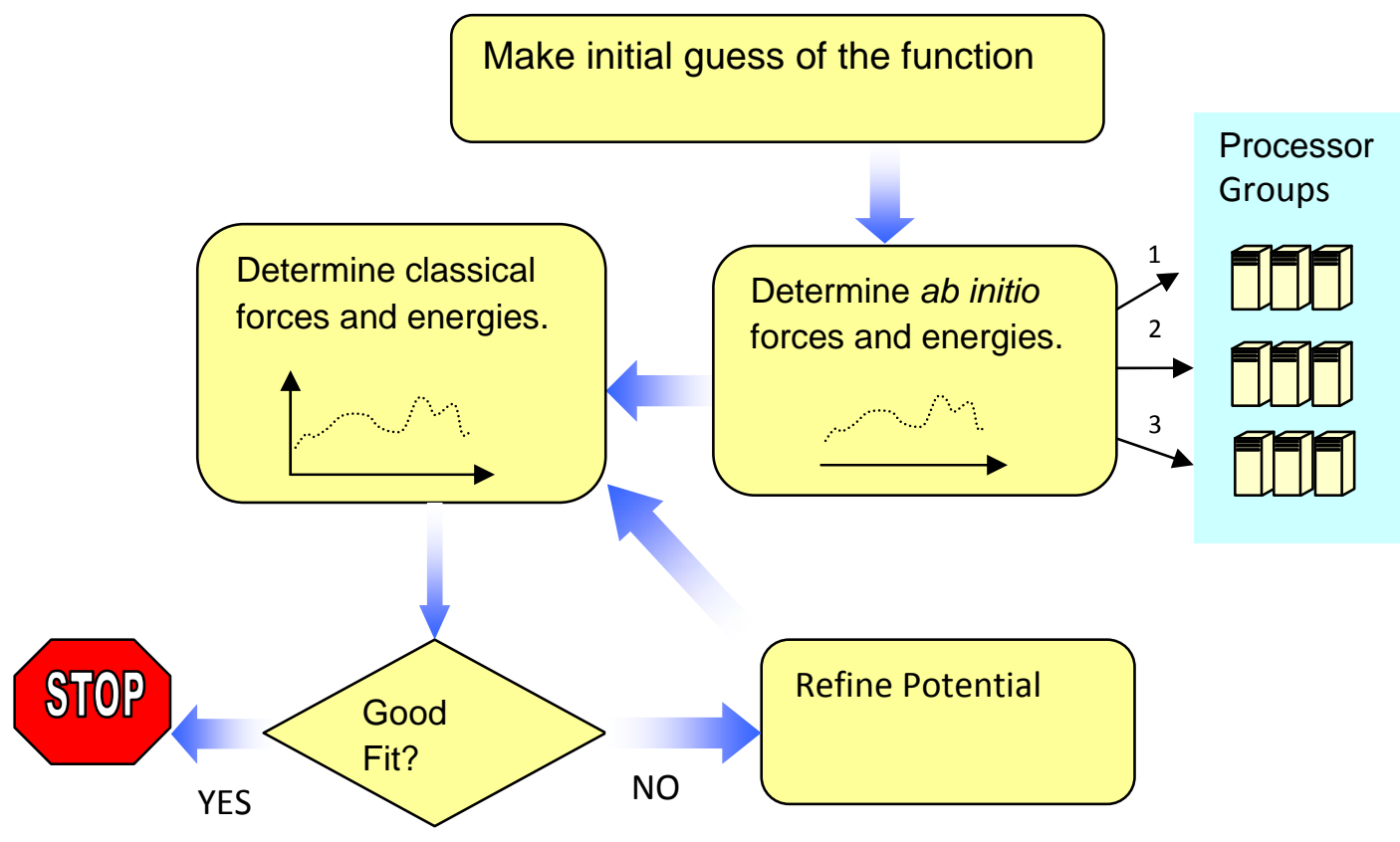

Figure 2. Flow-chart for the generation of transferable potentials

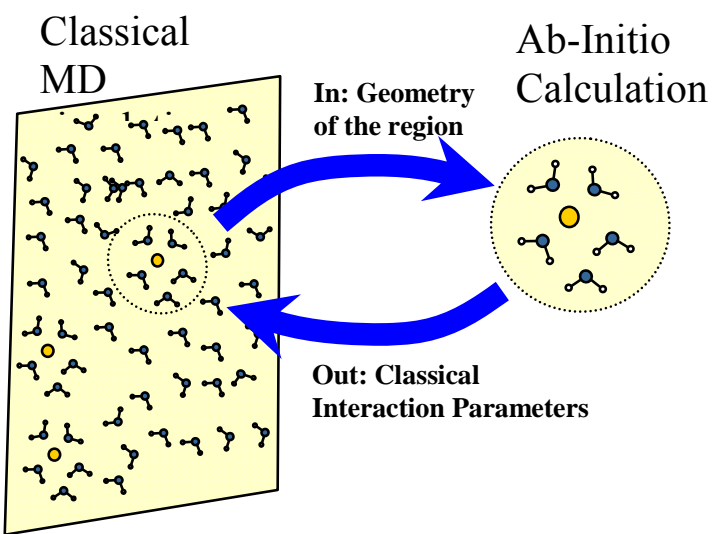

Figure 3. Schematic diagram of an approach to couple ab initio calculations with classical molecular dynamics. 

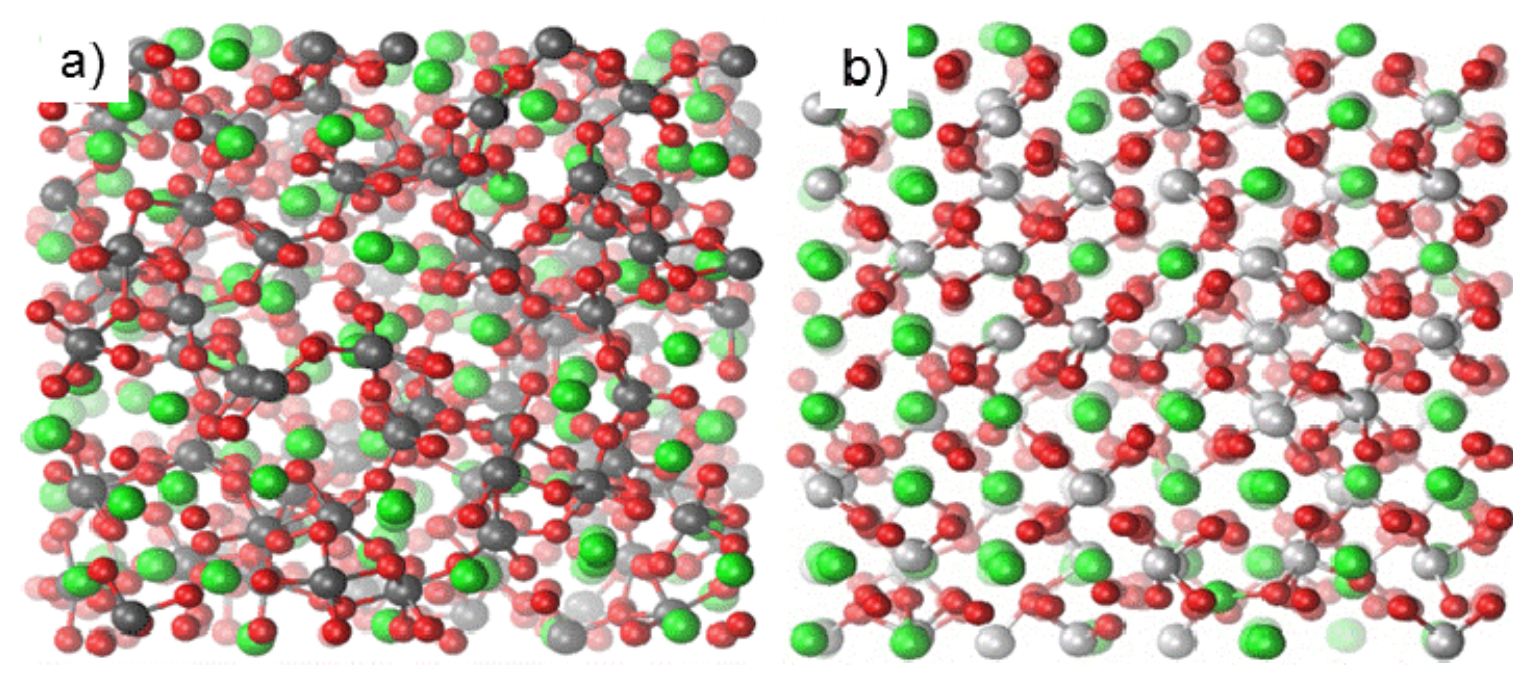

Figure 4. Atom projections from molecular dynamics simulation of defect accumulation in pyrochlore [55]. a) $\mathrm{Gd}_{2} \mathrm{Ti}_{2} \mathrm{O}_{7}$ is amorphous after cation Frenkel pairs were introduced in the lattice to a level of 0.63 displacements per atom (dpa); b) $\mathrm{Gd}_{2} \mathrm{Zr}_{2} \mathrm{O}_{7}$ is crystalline after defect accumulation to $1 \mathrm{dpa}$. The green, grey and red spheres represent $\mathrm{Gd}$, $\mathrm{Ti}$ or $\mathrm{Zr}$ and $\mathrm{O}$, respectively. 


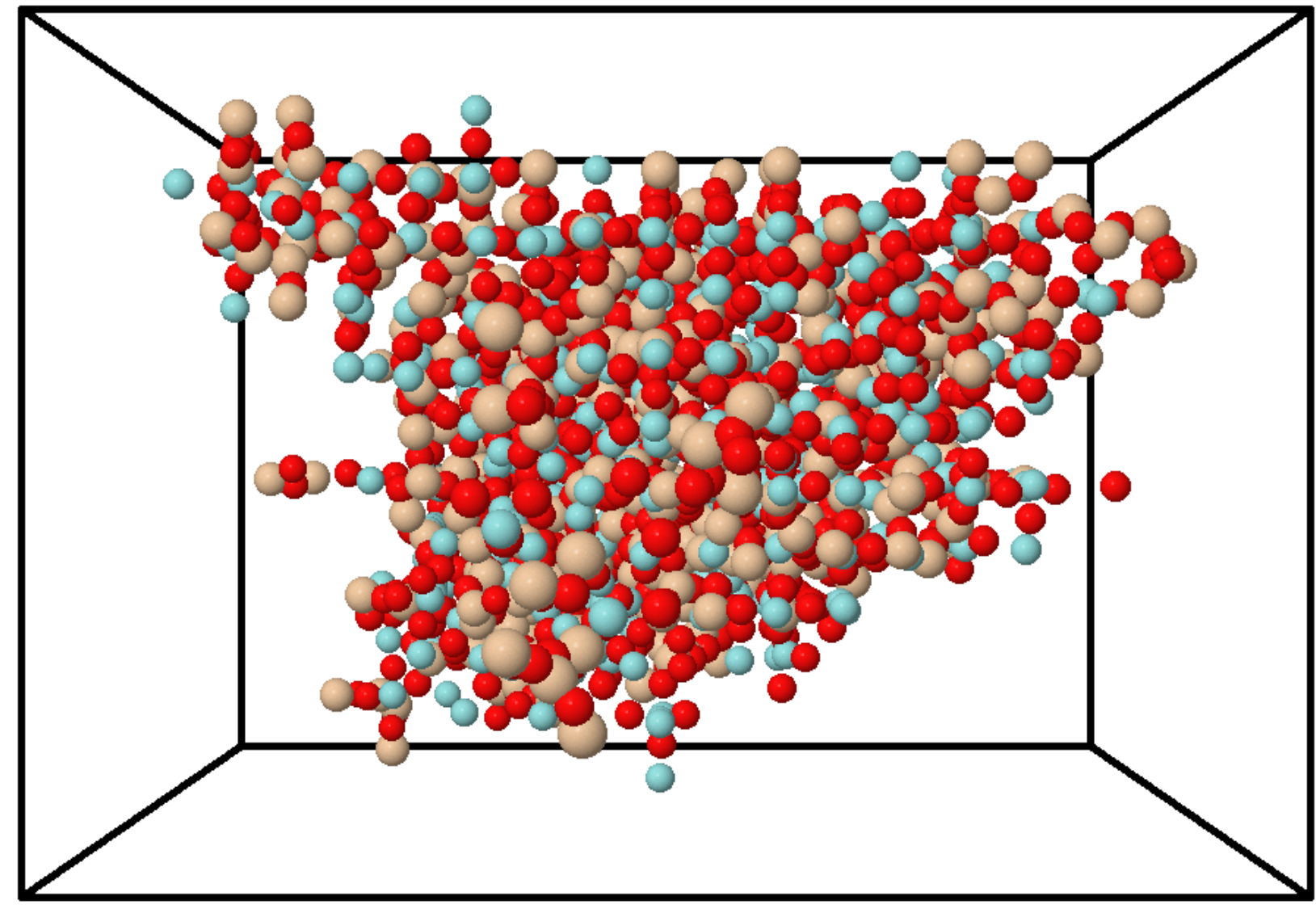

Figure 5. Perspective projection of defects created by a $30 \mathrm{keV} \mathrm{U}$ recoil in $\mathrm{ZrSiO}_{4}$. $\mathrm{Zr}$, Si and O defects are shown as blue, light brown and red spheres, respectively. The size of the box shown is about $13 \times 5 \times 4 \mathrm{~nm}$. The simulation cell is much larger. 


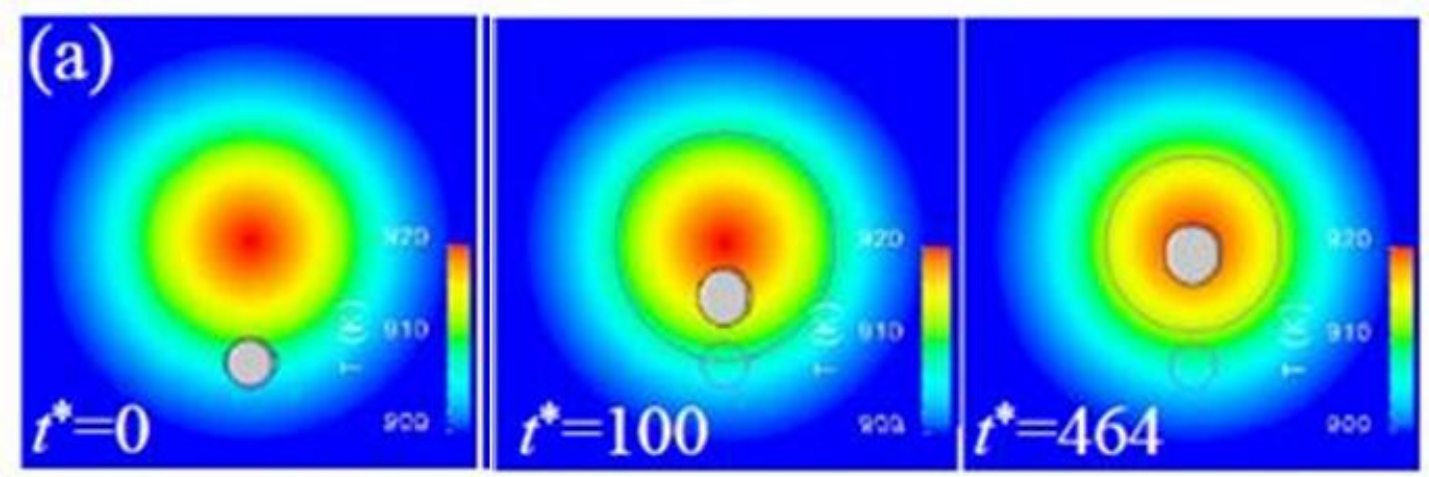

Figure 6. Phase field modeling of void migration and growth with time in nuclear fuels [86]. 


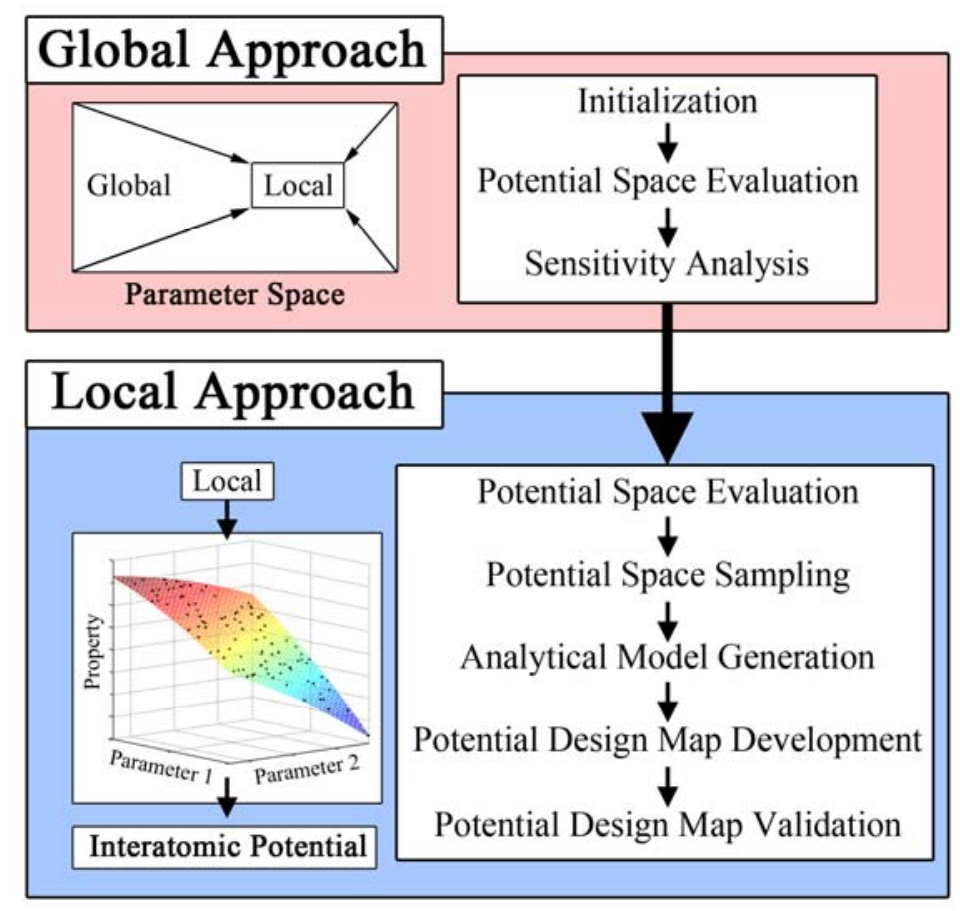

Figure 7. Schematic of the generalized framework for interatomic potential development showing the Global and Local Approach stages along with their individual steps [96]. 


\section{References}

[1] Sailor W C, Bodansky D, Braun C, Fetter S and van der Zwaan B 2000 A nuclear solution to climate change? Science 288(5469) 1177.

[2] Ewing R C, Weber W J and Clinard F W 1995 Radiation effects in nuclear waste forms for high-level radioactive waste Progress in Nuclear Energy 29(2) 63.

[3] Weber W J, Navrotksy A, Stefanovsky S, Vance E R and Vernaz E 2009 Materials science of high-level nuclear waste immobilization MRS Bulletin 34(1) 46.

[4] Hatch L P 1953 Ultimate disposal of radioactive wastes Amer. Sci. 41410.

[5] Roy R 1979 Science underlying radioactive waste management: status and needs Scientific Basis for Nuclear Waste Management 1 1, McCarthy G J ed., (New York: Plenum Press).

[6] Ringwood A E, Kesson S E, Ware N G, Hibberson W and Major A 1979 Immobilization of high level nuclear reactor wastes in SYNROC Nature 278219.

[7] Ewing R C and Lutze W 1991 High-level nuclear waste immobilization with ceramics Ceramics International 17287.

[8] Weber W J, Ewing R C, Catlow C R A, Diaz de la Rubia T, Hobbs L W, Kinoshita C, Matzke Hj, Motta A T, Nastasi M, Salje E K H, Vance E R and Zinkle S J 1998 Radiation effects in crystalline ceramics for the immobilization of high-level nuclear waste and plutonium J. Mater. Res. 131434.

[9] Ewing R C 1999 Nuclear waste forms for actinides Proc. Nat. Acad. Sci. 96(7) 3432.

[10] Ewing R C, Weber W J and Lian J 2004 Nuclear waste disposal-pyrochlore $\left(\mathrm{A}_{2} \mathrm{~B}_{2} \mathrm{O}_{7}\right)$ : Nuclear waste form for the immobilization of plutonium and "minor" actinides J. Appl. Phys. 955949.

[11] Lumpkin G R 2006 Ceramic waste forms for actinides Elements 2365.

[12] Wilde S A, Valley J W, Peck W H and Graham C M 2001 Evidence from detrital zircons for the existence of continental crust and oceans on the earth 4.4 Gyr ago Nature $\mathbf{4 0 9}$ 175.

[13] Kohn W and Sham L J 1964 Self-consistent equations including exchange and correlation effects Phys. Rev. 140 A1133

[14] Parr R G and Yang W 1989 Density-Functional Theory of Atoms and Molecules (New York: Oxford University Press)

[15] Dreizler R M and Gross E K U 1990 Density Functional Theory (Berlin: Springer)

[16] KohnW1999 Nobel lecture: electronic structure of matter-wave functions and density functionals Rev. Mod. Phys. 711253

[17] Martin R M 2004 Electronic Structure: Basic Theory and Practical Methods (Cambridge: Cambridge University Press)

[18] Mattsson A E, Schultz P A, Desjarlais M P, Mattsson T R, and Leung K 2005 Designing meaningful density functional theory calculations in materials science - a primer Modelling Simul. Mater. Sci. Eng. 13 R1.

[19] Hafner J, Wolverton C and Ceder G 2006 Toward computational materials design: The impact of density functional theory on materials research MRS Bulletin 31659. 
[20] Devanathan R, Van Brutzel L, Chartier A, Gueneau C, Mattsson A E, Tikare V, Bartel T, Besmann T, Stan M and Van Uffelen P 2010 Modeling and simulation of nuclear fuel materials Energy Environ. Sci. 31406.

[21] Anisimov V I, Zaanen J and Andersen O K 1991 Band theory and Mott insulators: Hubbard U instead of Stoner I Phys. Rev. B 44943.

[22] Dorado B, Freyss M and Martin G 2009 GGA plus U study of the incorporation of iodine in uranium dioxide European Phys. Journal B 69203.

[23] Devey A J 2011 First principles calculation of the elastic constants and phonon modes of $\mathrm{UO}_{2}$ using GGA plus U with orbital occupancy control J. Nucl. Mater 412301.

[24] Schreckenbach G and Shamov G 2010 Theoretical Actinide Molecular Science Accounts of Chemical Research 4319.

[25] Gale J D and Wright K 2010 Lattice dynamics from force fields as a technique for mineral physics Rev. Mineral. Geochem. 71391.

[26] Marx D and Hutter J 2009 Ab Initio Molecular Dynamics: Basic Theory and Advanced Methods (New York: Cambridge University Press)

[27] Jain A, Hautier G, Moore C J, Ong S P, Fischer C C, Mueller T, Persson K A and Ceder G 2011 A high-throughput infrastructure for density functional theory calculations Comput. Mater. Sci. $\mathbf{5 0} 2295$.

[28] Daw MS and Baskes M I 1984 Embedded atom method: Derivation and application to impurities, surfaces, and other defects in metals Phys. Rev. B 296443.

[29] van Duin A C T, Dasgupta S, Lorant F and Goddard W A III 2001 ReaxFF: A Reactive Force Field for Hydrocarbons J. Phys. Chem. A 1059396.

[30] Goddard W III, Merinov B, van Duin A, Jacob T, Blanco M, Molinero V, Jang S S and Jang Y H 2006 Multi-paradigm multi-scale simulations for fuel cell catalysts and membranes Molec. Simul. 32251.

[31] Zhang Q, Cagin T, van Duin A C T, Goddard W A, Qi Y and Hector L G 2004 Adhesion and nonwetting-wetting transition in the $\mathrm{Al} /$ alpha- $-\mathrm{Al}_{2} \mathrm{O}_{3}$ interface Phys. Rev. B 69 045423.

[32] van Duin A C T, Strachan A, Stewman S, Zhang Q and Goddard W A III 2003 ReaxFF $\mathrm{SiO}$ reactive force field for silicon and silicon oxide systems J. Phys. Chem. A 107 3803.

[33] Yu J, Sinnott S B and Phillpot S R 2007 Charge optimized many-body potential for the $\mathrm{Si} / \mathrm{SiO}_{2}$ system Phys. Rev. B 75085311.

[34] Shan T-R, Devine B D, Hawkins J M, Asthagiri A, Phillpot S R and Sinnott S B 2010 Second-generation charge-optimized many-body potential for $\mathrm{Si} / \mathrm{SiO}_{2}$ and amorphous silica Phys. Rev. B 82235302.

[35] Rustad J R 2011 Molecular models of surface relaxation, hydroxylation, and surface charging at oxide-water interfaces Rev. Mineral. Geochem. 42169.

[36] Mahadevan T S and Garofalini S H 2008 Dissociative chemisorption of water onto silica surfaces and formation of hydronium ions J. Phys. Chem. C 1121507.

[37] Cygan R T, Liang J L and Kalinichev A G 2004 Molecular models of hydroxide, oxyhydroxide, and clay phases and the development of a general force field J. Phys. Chem. B 1081255. 
[38] Hughes Z E, Carrington L A, Raitieri P and Gale J D 2011 A computational investigation into the suitability of purely siliceous zeolites as reverse osmosis membranes J. Phys. Chem. C 1154063.

[39] Dick B G Jr. and Overhauser A W 1958 Theory of the dielectric constants of alkali halide crystals Phys. Rev. 11290.

[40] Lewis G V and Catlow C R A 1985 Potential models for ionic oxides J. Phys. C: Solid State Phys. 181149.

[41] Bush T S, Gale J D, Catlow C R A and Battle P D 1994 Self-consistent interatomic potentials for the simulation of binary and ternary oxides J. Mater. Chem. 4831.

[42] Minervini L, Grimes R W and Sickafus K E 2000 Disorder in pyrochlore oxides J. Am. Ceram. Soc. 831873.

[43] Ercolessi F and Adams J B 1994 Interatomic potentials from first-principles calculations: the force-matching method Europhys. Lett. 26583.

[44] Landa A, Wynblatt P, Siegel D J, Adams J B, Mryasov ON and Liu X.-Y. 2000 Development of glue-type potentials for the Al-Pb system: phase diagram calculation Acta. Mater. 481753.

[45] Lenosky T J, Sadigh B, Alonso E, Bulatov V V, de la Rubia T D, Kim J, Voter A F and Kress J D 2000 Highly optimized empirical potential model of silicon Modelling Simul. Mater. Sci. Eng. 8825.

[46] Lin H and Truhlar D G 2007 QM/MM: what have we learned, where are we, and where do we go from here? Theor. Chem. Acc. 117185.

[47] Kerdcharoen T, Liedl K R and Rode B M 1996 A QM/MM simulation method applied to the solution of $\mathrm{Li}^{+}$in liquid ammonia Chem. Phys. 211313.

[48] Huang P and Carter E A 2008 Advances in correlated electronic structure methods for solids, surfaces, and nanostructures Ann. Rev. Phys. Chem. 59261.

[49] Fichthorn K A and Weinberg W H 1991 Theoretical foundations of dynamical Monte Carlo simulations J. Chem. Phys. 951090.

[50] Boettinger W J, Warren J A, Beckermann C and Karma A 2002 Phase field simulation of solidification Ann. Rev. Mater. Res. 32163.

[51] Sickafus K E, Minervini L, Grimes R W, Valdez J A, Ishimaru M, Li F, McClellan K J and Hartmann T 2000 Radiation tolerance of complex oxides Science 289748.

[52] Sickafus K E, Grimes R W, Valdez J A, Cleave A, Tang M, Ishimaru M, Corish S M, Stanek C R and Uberuaga B P 2007 Radiation-induced amorphization resistance and radiation tolerance in structurally related oxides Nat. Mater. 6217.

[53] Chartier A, Catillon G and Crocombette J P 2009 Key role of the cation interstitial structure in the radiation resistance of pyrochlores Phys. Rev. Lett. 102155503.

[54] Crocombette J P and Chartier A 2007 Molecular dynamics studies of radiation induced phase transitions in $\mathrm{La}_{2} \mathrm{Zr}_{2} \mathrm{O}_{7}$ pyrochlore Nucl. Instrum. Meth. B 255158.

[55] Devanathan R, Weber W J and Gale J D 2010 Radiation tolerance of ceramics -insights from atomistic simulation of damage Energy Environ. Sci. 31551.

[56] Devanathan R and Weber W J 2008 Dynamic annealing of defects in irradiated zirconiabased ceramics J. Mater. Res. 23593.

[57] Tuller H L 1992 Mixed ionic-electronic conduction in a number of fluorite and pyrochlore compounds Solid State Ionics 52135. 
[58] Rushton M J D, Stanek C R, Cleave A R, Uberuaga B P, Sickafus K E and Grimes R W 2007 Simulation of defects and defect processes in fluorite and fluorite-related oxides: Implications for radiation tolerance Nucl. Instrum . and Meth. B 255151.

[59] Devanathan R and Weber W J 2005 Insights into the radiation response of pyrochlores from calculations of threshold displacement events J. Appl. Phys. 98086110.

[60] Smith R, Bacorisen D, Uberuaga B P, Sickafus K E, Ball J A and Grimes R W 2005 Dynamical simulations of radiation damage in magnesium aluminate spinel, $\mathrm{MgAl}_{2} \mathrm{O}_{4}$ J. Phys.: Condens. Matter 17875.

[61] Trachenko K, Dove M T and Salje E K H 2001 Atomistic modelling of radiation damage in zircon J. Phys.: Condens. Matter 131947.

[62] Trachenko K, Dove M T and Salje E K H 2002 Structural changes in zircon under a-decay irradiation Phys. Rev. B 65180102.

[63] Trachenko K, Pruneda M, Artacho E and Dove MT 2004 Radiation damage effects in the perovskite $\mathrm{CaTiO} 3$ and resistance of materials to amorphization Phys. Rev. B 70 134112.

[64] Trachenko K, Dove M T, Geisler T, Todorov I and Smith B 2004 Radiation damage effects and percolation theory J. Phys.: Condens. Matter 16 S2623.

[65] Trachenko K, Pruneda M, Artacho E and Dove M T 2005 How the nature of the chemical bond governs resistance to amorphization by radiation damage Phys. Rev. B 71184104 .

[66] Trachenko K, Todorov I T, Dove M T, Artacho E and Smith W 2006 Atomistic simulations of resistance to amorphization by radiation damage Phys. Rev. B 73174207.

[67] Devanathan R, Corrales L R, Weber W J, Chartier A and Meis C 2006 Molecular dynamics simulation of energetic uranium recoil damage in zircon Molec. Simul. 321069.

[68] Devanathan R and Weber W J 2007 Radiation effects in a model ceramic for nuclear waste disposal JOM 5932.

[69] Devanathan R 2009 Radiation damage evolution in ceramics Nucl. Instrum. and Meth. B 2673017.

[70] Yu J, Devanathan R and Weber W J 2009 Unified interatomic potential for zircon, zirconia and silica systems J. Mater. Chem. 193923.

[71] Heinisch HL and Weber W J 2005 Computational model of alpha-decay damage accumulation in zircon Nuclear Instrum. Meth. B 228293.

[72] Rong Z, Gao F, Weber W J and Hobler G 2007 Monte Carlo simulations of defect recovery within a $10 \mathrm{keV}$ collision cascade in 3C-SiC J. Appl. Phys. 102103508.

[73] Pakarinen O H, Djurabekova F and Nordlund K 2010 Density evolution in formation of swift heavy ion tracks in insulators Nuclear Instrum. Meth. B 2683163.

[74] Crocombette, J P 2009 Can thermal spike calculations reproduce displacement cascades? Nucl. Instrum. Meth. B 2673152.

[75] Zhang J, Lang M, Ewing R C, Devanathan R, Weber W J and Toulemonde M 2010 Nanoscale phase transitions under extreme conditions within an ion track J. Mater. Res. 251344.

[76] Harding J H and Harris D J 2001 Simulation of grain-boundary diffusion in ceramics by kinetic Monte Carlo Phys. Rev. B 63094102.

[77] Bates J K, Bradley J P, Teetsov A, Bradley C R and Buchholtz ten Brink M 1992 Colloid formation during waste form reaction: Implications for nuclear waste disposal Science 256649. 
[78] Nangia S and Garrison B J 2010 Theoretical advances in the dissolution studies of mineralwater interfaces Theor. Chem. Acc. 127271.

[79] Xiao Y and Lasaga A C 1996 Ab initio quantum mechanical studies of the kinetics and mechanisms of quartz dissolution: $\mathrm{OH}^{-}$catalysis Geochim. Cosmochim Acta 602283.

[80] Criscenti L J, Kubicki J D and Brantley S L 2006 Silicate glass and mineral dissolution: calculated reaction paths and activation energies for hydrolysis of a $\mathrm{Q}^{3} \mathrm{Si}$ by $\mathrm{H}_{3} \mathrm{O}^{+}$ using ab initio methods J Phys. Chem. A 110198.

[81] Du Z and de Leeuw N H 2006 Molecular dynamics simulations of hydration, dissolution and nucleation processes at the $\alpha$-quartz (0001) surface in liquid water Dalton Trans. 2623.

[82] Mahadevan T S and Garofalini S H 2008 Dissociative chemisorption of water onto silica surfaces and formation of hydronium ions J. Phys. Chem. C 1121507.

[83] Lasaga A C and Luttge A 2005 Kinetic Justification of the solubility product: Application of a general kinetic dissolution model J. Phys. Chem. B 1091635.

[84] Nangia S and Garrison B J 2009 Advanced Monte Carlo approach to study evolution of quartz surface during the dissolution process J. Am. Chem. Soc. 1319538.

[85] Aertsens M 2009 Long-term behaviour of nuclear waste glass: Monte Carlo simulations Scientific report for WP5 Task 1 of RP.WD.008 SCK•CEN-ER-109.

[86] Hu S, Li Y, Sun X, Gao F, Devanathan R, Henager C H and Khaleel M 2010 Application of the phase field method in predicting gas bubbles microstructure evolution in nuclear fuels Int. J. Mat. Res. 101515.

[87] Li Y, Hu S, Sun X, Gao F, Henager C H and Khaleel M 2010 Phase-field modeling of void migration and growth kinetics in materials under irradiation and temperature field $\mathrm{J}$. Nucl. Mater. 407119.

[88] Li Y, Hu S, Sun X, Gao F, Henager C H and Khaleel M 2011 Phase-field modeling of void evolution and swelling in materials under irradiation, SCIENCE CHINA: Physics, Mechanics \& Astronomy 54856.

[89] Rokkam S, El-Azab A, Millett P and Wolf D 2009 Phase field modeling of void nucleation and growth in irradiated metals Modelling Simul. Mater. Sci. Eng. 17064002.

[90] Devanathan R, Sickafus K E, Weber W J and Nastasi M 1998 Effects of ionizing radiation in ceramics J. Nucl. Mater. 253113.

[91] Xiao H Y, Gao F and Weber W J 2010 Threshold displacement energies and defect formation energies in $\mathrm{Y}_{2} \mathrm{Ti}_{2} \mathrm{O}_{7}$ J. Phys.: Condens. Matter 22415801.

[92] Lucas G and Pizzagalli L 2007 Ab initio molecular dynamics calculations of threshold displacement energies in silicon carbide Phys. Rev. B 72161202.

[93] Gao F, Xiao H Y, Zu X T, Posselt M and Weber W J 2009 Defect-enhanced charge transfer by ion-solid interactions in sic using large-scale ab initio molecular dynamics simulations Phys. Rev. Lett. 103027405.

[94] Sutton A P, Todorov T N, Cawkwell M J and Hoekstra J 2001 A simple model of atomic interactions in noble metals based explicitly on electronic structure Phil. Mag. 811833.

[95] Zhou X W and Doty F P 2008 Embedded-ion method: An analytical energy-conserving charge-transfer interatomic potential and its application to the La-Br system Phy. Rev. B 78224307. 
[96] Tschopp M A, Solanki K N, Baskes M I, Gao F, Sun X and Horstemeyer M F 2011 Generalized framework for interatomic potential design: Application to Fe-He system J. Nucl. Mater. doi:10.1016/j.jnucmat.2011.08.003. 